\title{
Descrição de Xestoblatta mamorensis sp. nov. (Blattellidae: Blattaria), do Estado de Rondônia, Brasil
}

Sonia Maria LOPES$^{1}$, Edivar Heeren de OLIVEIRA ${ }^{1}$

\section{RESUMO}

Xestoblatta mamorensis sp. nov. é descrita do Estado de Rondônia (Brasil). Foram utilizadas para sua determinação a morfologia das placas genitais e genitália do macho e presença de especialização abdominal em mais de um segmento.

PALAVRAS-CHAVE

Xestoblatta mamorensis sp. nov., Blattaria, Rondônia, Taxonomia.

\section{Description of Xestoblatta mamorensis sp. nov. (Blattellidae: Blattaria), from Rondônia State, Brazil.}

ABSTRACT

Xestoblatta mamorensis sp. nov. is described from Rondônia State (Brazil) with analysed the morphology of genital pieces and male genitalia and the abdominal specialization in more of one segment.

KEYWORDS

Xestoblatta mamorensissp. nov., Blattaria, Rondônia, Taxonomy.

${ }^{1}$ Departamento de Entomologia, Museu Nacional, UFRJ, Quinta da Boa Vista, São Cristóvão, RJ, Brasil, CEP 20940-040, sonialf@acd.ufrj.br 


\section{ACTA AMAZONICA}

DESCRIÇÃO DE Xestoblatta mamorensis SP. NOV. (BLATTELLIDAE: BLATTARIA), DO ESTADO DE RONDÔNIA, BRASIL
O gêneroXestoblatta foi descrito por Hebard (1916). Reúne atualmente 29 espécies, sendo que 12 são brasileiras, das quais 10 foram registradas na região da Amazônia, e as demais na região sudeste e centro-oeste. Estão distribuídas desde a Costa Rica até o Brasil, no qual não ultrapassa o paralelo $25^{\circ} \mathrm{Sul}$ (Rocha e Silva-Albuquerque \& Fraga, 1975).

Neste trabalho é acrescentada uma espécie nova ao gênero e é registrada pela primeira vez a ocorrência do gênero no Estado de Rondônia.

O espécime foi analisado morfologicamente de acordo com as técnicas utilizadas e descritas em Lopes \& Oliveira (2000) e depositado na coleção do Departamento de Entomologia do Museu Nacional, Universidade Federal do Rio de Janeiro (MNR).

A terminologia utilizada segue Mckittrick (1964). A análise do material tem por base a retirada das placas genitais do exemplar macho. Após análise, as placas e peças genitais internas foram guardadas em "microvials", contendo glicerina e devidamente acondicionadas junto ao exemplar respectivo, montado em alfinete entomológico, técnica desenvolvida por Gurney et al. (1964).
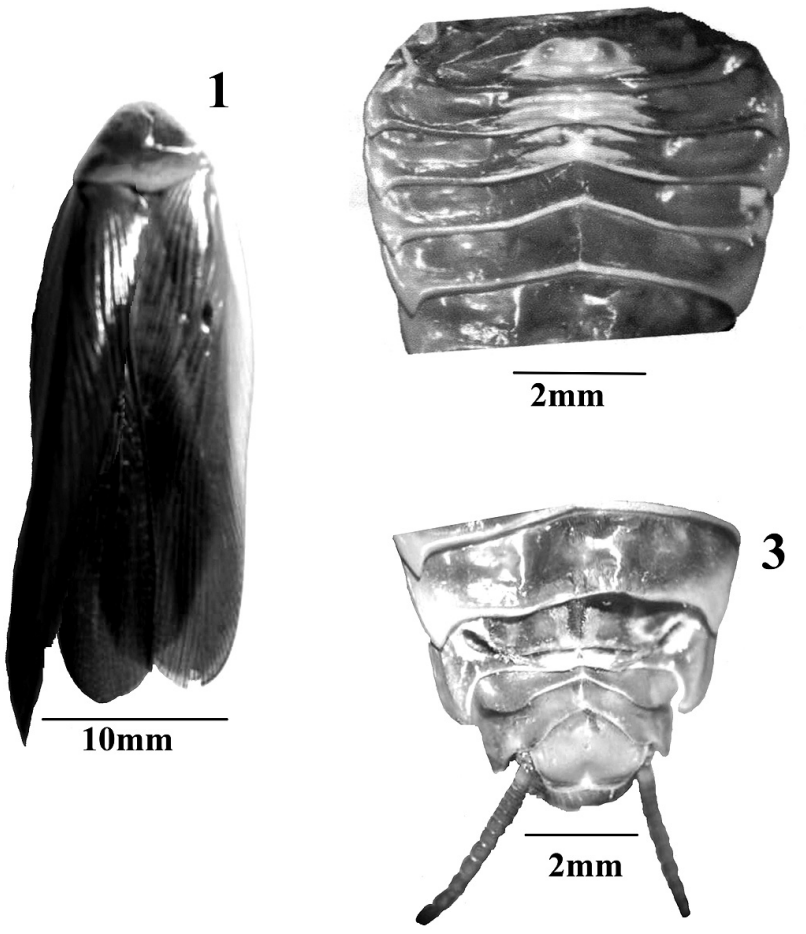

Figuras 1 a 3 - Xestoblatta mamorensis sp. nov.. 1) Habitus, vista dorsal; 2) abdome com especialização nos três primeiros tergitos, vista dorsal; 3) Abdome placa supra-anal com especialização no $9^{\circ}$ tergito lateralmente e proeminência no $11^{\circ}$ tergito antes da placa supra-anal, vista dorsal.

\section{Xestoblatta mamorensis sp. nov.}

\section{(Figs. 1-8)}

Coloração geral castanho-brilhante (Fig. 1). Cabeça castanhoclara, amarelada e brilhante; olhos descoloridos com entorno castanho; manchas ocelares esbranquiçadas; palpos maxilares com nuances castanho-escuras no quarto e quinto segmentos; pronoto com disco central levemente mais escuro; pernas e tégminas castanhas com campo marginal mais claro.

Dimensões (mm). Holótipo macho. Comprimento total 30,0; comprimento do pronoto 5,0; largura do pronoto 8,0; comprimento da tégmina 25,0; largura da tégmina 7,0.

Cabeça triangular e alongada; vértice encoberto pelo pronoto; espaço interocular pouco menor que a área que separa as bases das antenas; ocelos bem marcados; olhos relativamente pequenos; palpos maxilares desenvolvidos, com o terceiro segmento levemente maior que os demais, quinto segmento dilatado e bastante tomentoso; antenas longas ultrapassando em comprimento o ápice do abdome.

Tórax. Pronoto com convexidade suave, transverso, com ápice arredondado, base levemente angular, abas laterais amplas e levemente arredondadas. Tégminas desenvolvidas, alongadas, com largura maior no terço apical, campo marginal bem marcado e suavemente côncavo; campo escapular estreito e oblíquo; campo discoidal amplo e longitudinal, campo anal amplo e alongado com oito veias axilares. Asas desenvolvidas, campo anterior oblíquo com nervuras simples no terço basal e três ou mais nervuras ramificadas próximo ao ápice; triângulo apical não desenvolvido, e campo anal dobrado em leque. Pernas apresentando coxas largas e trocânteres desenvolvidos; fêmur anterior com a face ântero-ventral com quatro espinhos desenvolvidos até a região mediana, seguindo em direção ao ápice, por uma série de sete espinhos, que decrescem gradativamente em tamanho, apresentando mais três apicais grandes; face pósteroventral com quatro espinhos desenvolvidos e espaçados, mais um espinho apical grande. Fêmures médio e posterior semelhantes, apresentando em ambas as faces ventrais, cerca de seis a sete espinhos sendo um apical; pulvilos bem desenvolvidos; arólio presente, unhas simétricas e sem especialização havendo pequenas ondulações ventralmente na face interna, um espinho genicular forte nos dois últimos fêmures.

Abdome com modificação tergal nos três primeiros tergitos (Fig. 2), no sétimo segmento com projeções laterais que envolvem o oitavo segmento, no nono e no décimo representado pela placa supra-anal dorsalmente (Fig. 3). Essas diferenciações são visíveis no exemplar seco, quando desesclerotinizado pela potassa se tornam de difícil visualização, daí a representação com fotos digitalizadas. Placa supra-anal projetada entre os cercos e com ápice levemente bilobado (Fig. 4). Placa subgenital assimétrica com o bordo apical sinuoso e com pilosidade concentrada na parte mediana apical da placa; estilos ciliados com ápices espiniformes, diferenciados em forma e comprimento, inseridos próximos às laterais da placa. (Fig. 6). 


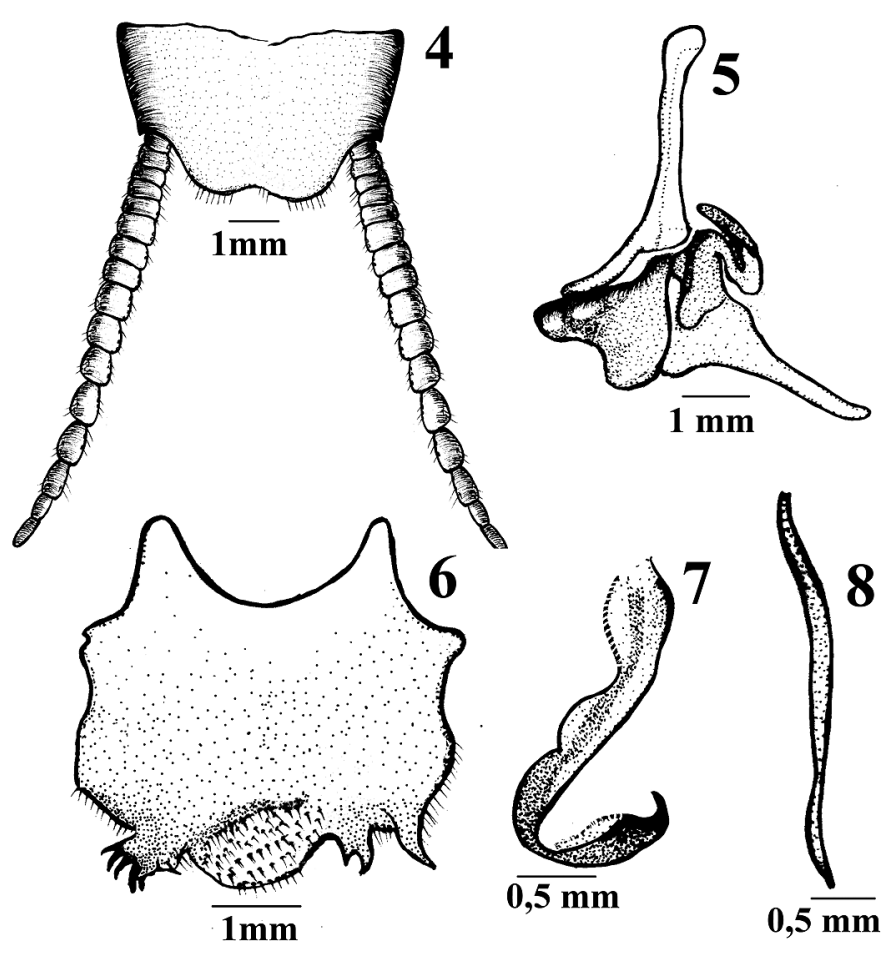

Figuras 4 a 8 - Xestoblatta mamorensis sp. nov. 4) placa supraanal, vista dorsal; 5) falômero direito (R3), vista dorsal; 6) placa subgenital, vista ventral; 7) falômero esquerdo (L3) em forma de gancho; 8) esclerito mediano (L2vm).

Genitália com o falômero direito (R3) medianamente esclerotinizado (Fig. 5); esclerito mediano afilado (Fig. 8); falômero esquerdo em gancho com o ápice voltado para o interior da peça e com ondulações no corpo médio apicalmente (Fig. 7).
Material examinado: Holótipo macho: BRASIL: Rondônia, Reserva Mamoré, 25/01/1998, s/coletor.

Etimologia: $\mathrm{O}$ nome da espécie se deve à localidade de origem do exemplar.

Diagnose: A espécie se diferencia de todas as outras espécies descritas pela modificação tergal apresentada no abdome, pela placa subgenital e genitália.

\section{BIBLIOGRAFIA CITADA}

Gurney, A.B., Kramer, J. P.; Steyskal, G. C. 1964 - Some Techniques for the Preparation, Study and Storage in Microvials of Insect Genitalia. Annals of the Entomological Society of America, 57(2):240-242.

Hebard, M. 1916. Studies in the group Ischnopterites (Orthoptera, Blattidae, Pseudomopinae). Transactions American Entomological Society, 42: 337-383.

Lopes, S. M.; Oliveira, E. H. 2000. Espécie nova de Blaberus Serville, 1831 do Estado de São Paulo, Brasil (Blaberidae, Blaberinae). Boletim do Museu Nacional, Rio de Janeiro, nova série, Zoologia, 415:1-4.

Mckittrick. F.A., 1964. Evolutionary studies of cockroaches. Cornell University Agricultural Experiment Station Memoir, 389:1-197.

Rocha e Silva-Albuquerque, I.; Fraga, C. R. C. 1975. Estudo sobre o gênero Xestoblatta Hebard, 1916 (Blattariae). Boletim do Museu Paraense Emílio Goeldi, nova série: Zoologia, 79:1-14.

RECEBIDO EM 11/02/2004 ACEITO EM 26/12/2005 
